\title{
Erratum to: Are irreversible morphological signs of portal hypertension in neurological form of Wilson's disease associated with treatment delay? A pilot study
}

\author{
D. B. Kozic $\cdot$ R. Semnic $\cdot$ I. Petrovic $\cdot$ \\ M. Svetel $\cdot$ J. Ostojic $\cdot$ V. S. Kostic
}

Published online: 9 March 2012

(c) Belgian Neurological Society 2012

\section{Erratum to: Acta Neurol Belg}

DOI 10.1007/s13760-012-0025-1

In the original published article, the word "morpholocical" in the article title and the authors' affiliations are incorrect.

The correct title should read:

Are irreversible morphological signs of portal hypertension in neurological form of Wilson's disease associated with treatment delay? A pilot study

The correct author affiliations are given here.

D. B. Kozic, R. Semnic, J. Ostojic

Oncology Institute of Vojvodina, University of Novi Sad School of Medicine, Sremska Kamenica, Novi Sad, Serbia e-mail: dusko.b.kozic@gmail.com

I. Petrovic, M. Svetel, V. S. Kostic Institute of Neurology, University of Belgrade School of Medicine, Belgrade, Serbia

The authors regret the errors.

The online version of the original article can be found under doi:10.1007/s13760-012-0025-1.

D. B. Kozic $(\bowtie) \cdot$ R. Semnic · J. Ostojic Oncology Institute of Vojvodina, University of Novi Sad School of Medicine, Sremska Kamenica, Novi Sad, Serbia e-mail: dusko.b.kozic@gmail.com

I. Petrovic $\cdot$ M. Svetel · V. S. Kostic Institute of Neurology, University of Belgrade School

of Medicine, Belgrade, Serbia 